\title{
Opinião
}

\section{A IMPORTÂNCIA DA PARTICIPAÇÃO DO PARCEIRO NO PLANEJAMENTO FAMILIAR}

\author{
Maria Socorro de Figueiredo Feitosa (1)
}

Maria Engracia Loiola (2)

Ao controle e decisão de um casal sobre gerar ou não filhos, e mesmo quando fazê-lo, chamamos de planejamento familiar. Esse processo utiliza-se de métodos diversos de contracepção e de orientações específicas acerca da fisiologia sexual e reprodutiva; métodos disponibilizados, seus benefícios e desvantagens; como também da prevenção das Doenças Sexualmente Transmissíveis - DST's.

Assim sendo, o presente estudo pretende enfatizar a importância que a inclusão masculina representa em todo o processo de estruturação da família. No atual contexto de elevadas incidência e prevalência de DST's e de gravidez indesejada, a implementação do planejamento familiar nas unidades básicas de saúde tornou-se essencial para o controle das problemáticas de saúde e social supracitadas.

Embora o próprio termo evidencie a necessidade da presença da figura masculina no planejamento familiar, o que pode ser observado na realidade é o comparecimento apenas das mulheres nesse tipo de consulta. Torna-se, portanto, de fundamental relevância, abordar a importância do envolvimento do parceiro no planejamento familiar, tanto sob o ponto de vista da eficácia dos métodos, como também da adesão às medidas preventivas.

Segundo o manual do Ministério da Saúde, planejamento familiar consiste no direito à informação, à assistência especializada e acesso aos recursos que permitam optar livre e conscientemente por ter ou não filhos, o número, o espaçamento entre eles e a escolha do método anticoncepcional mais adequado, sem qualquer tipo de coação.

A participação efetiva do casal é de suma importância para se escolher a melhor forma de contracepção junto aos profissionais de saúde, haja vista a necessidade de um consenso do casal para se aliar a adesão do método selecionada à realidade conjugal afetiva, social, financeira e ideológica. 
O maior engajamento da mulher no planejamento familiar justifica-se pelo elevado comprometimento fisiológico e social que uma gravidez não planejada pode acarretar, assim como à maior preocupação com o corpo e com a saúde, característica inerente dessa população. Já a participação pouco significativa do sexo masculino nos programas de planejamento familiar juntamente com os tabus sociais que dificultam o diálogo aberto sobre sexualidade entre o casal, atuam como barreiras na adesão do método escolhido para contracepção, uma vez que os anseios e as preferências sexuais de ambos os cônjuges apresentam-se incompatíveis, na maioria das vezes.

Diante desta realidade, propomos apresentar pontos que justifiquem a importância da participação do parceiro no planejamento familiar, enfatizando essa participação como meio elementar de focalizar a assistência à saúde e facilitar a escolha do método anticoncepcional mais adequado, estimulando em concomitância o diálogo do casal sobre sexualidade e viabilizando ações educativas com ênfase nessa temática.

Desde a antiguidade o homem é conhecedor de alguns métodos para se evitar a gravidez. Utilizava-se dos chamados "métodos naturais" que incluem a tabelinha, a observação do muco cervical, temperatura corporal, dentre outros. Muitos destes são, ainda hoje, difundidos e utilizados em todo o mundo. No entanto a sua eficácia é bastante questionável, devido às diferenças fisiológicas existentes entre as mulheres. Além disso, com o advento das doenças sexualmente transmissíveis, o homem foi forçado a descobrir métodos que além de evitar a gravidez também protegessem contra essas doenças.

O desenvolvimento tecnológico possibilitou a descoberta de diversos meios que objetivam evitar a gravidez bem como prevenir o aparecimento de DST's. Os métodos atualmente disponíveis no mercado podem ser classificados de acordo com o método de atuação em: métodos de barreira (preservativos - masculino e feminino, diafragma); hormonais (anticoncepcionais orais, injetáveis e cutâneos); químicos (espermicidas); e físicos (DIU, laqueadura, vasectomia). No entanto, cada um deles é portador de vantagens e desvantagens. Alguns têm eficácia reduzida, efeitos colaterais, alto custo, etc. Estes podem ser utilizados isolada ou conjuntamente, a depender do objetivo da sua utilização, bem como da preferência do casal.

Tais métodos podem ser utilizados isolada ou conjuntamente, a depender dos objetivos do casal. Com base nisso, faz-se necessário que o homem e a mulher conheçam as particularidades de cada método, pois nem todos são capazes de evitar a gravidez ao mesmo tempo que previnem contra as DST's. 
Apesar da enorme diversidade de produtos disponíveis no comércio, o serviço público de saúde apresenta uma disponibilidade bastante reduzida desses materiais. Encontramos na rede básica apenas os anticoncepcionais orais e injetáveis, preservativos (masculino e em menor proporção o feminino) e alguns métodos irreversíveis como a laqueadura e a vasectomia.

Frente à complexidade deste processo, torna-se essencial a participação de um profissional (médico ou enfermeiro) da unidade básica como mediador deste processo. Este profissional deve oferecer informações claras e objetivas acerca da disponibilidade, modos de usar, contra-indicações, bem como adequabilidade às peculiaridades de cada caso.

No entanto, para que isso possa ocorrer, torna-se imperativo o comparecimento de ambos os parceiros à UBS para que estes decidam, conjuntamente, qual ou quais os métodos que melhor se adequam à sua condição

Assim sendo, como esse processo envolve o casal, não cabe somente a mulher a busca e utilização de tais métodos. No entanto, esbarra-se na resistência do homem em comparecer à unidade de saúde para o planejamento. Esta atitude gera diversas situações desagradáveis para a mulher. Dentre elas a gravidez indesejada.

A gravidez indesejada é caracterizada pela concepção de um ser no ambiente em que o casal ou um dos parceiros não deseja ter filhos, ou acham que o momento não é propício para o acolher e acompanhar o desenvolvimento de um novo indivíduo. Este processo exige mudança nas situações financeira, psicológica e social do casal.

No Brasil, o número de gravidezes indesejadas vem crescendo em razão, principalmente, da falta de conhecimento sobre os métodos contraceptivos e preconceito, principalmente dos homens em relação ao seu uso, bem como da realização do planejamento familiar, dentre outros fatores.

Apesar da mulher ser apontada pela sociedade, composta principalmente por indivíduos "machistas", como a maior responsável pela gravidez indesejada, o homem também tem grande responsabilidade nesse processo. Por isso, ele deve ter consciência das transformações que essa situação propicia e deve saber como evitá-la.

Esse problema favorece o surgimento de patologias como depressão pós-parto, como também agravos situacionais, dentre eles a separação do casal e, em alguns casos, a responsabilidade do filho passa para uma terceira pessoa que pode ser da família ou não, no caso a adoção.

No planejamento familiar o casal é orientado quanto ao uso de métodos contraceptivos, o qual tem como um de seus objetivos evitar a gravidez indesejada. Através 
desse programa é possível resolver tal problema e formular uma família bem estruturada que favoreça o crescimento e desenvolvimento satisfatório de todos os membros.

Um outro aspecto que merece atenção dos especialistas e que deve ser trabalhado no planejamento familiar são as doenças sexualmente transmissíveis.

De acordo com AZEVEDO (2002) existem cerca de 20 agentes infecciosos que podem ser causadores das DST'S. As principais DST's são: Aids, blenorragia,cancro, candidíase genital, citomegalovírus, clamídia, donovanose, hepatite, herpes genital, linfogranuloma inguinal, oftalmia neonatal, phititiase do púbis, sífilis, tricomoníase urogenital, vaginose, infecção pelo Papiloma Vírus Humano, infecção pelo Vírus do Molusco contagioso e infecção pelo Vírus T-Linfotrópico Humano.

Os principais sintomas das DST'S incluem corrimento abundante, odor fétido, prurido e ulcerações nos órgãos genitais, ardor ao urinar e dispaurenia. Entretanto, muitas vezes as DST's não apresentam sintomas visíveis ou imediatos, necessitando de diagnóstico mais aprofundado.

O uso de preservativos é a principal forma de evitar o risco de contaminação pelos vários microorganismos que causam as DST’s. Embora eles sejam métodos contraceptivos, a sua função mais importante é a prevenção. Portanto, é necessário que o casal, ao escolher o método contraceptivo, considere a finalidade do preservativo, devendo usá-lo em associação a outras formas de contracepção.

O tratamento para a maioria das DST's é realizado com antibióticos, que são eficientes somente quando o diagnóstico é feito corretamente, com o auxílio de exames clínicos e de laboratório (AZEVEDO, 2002). É importante ressalvar que para a eficácia do tratamento é mandatória a participação de parceiro sexual, tendo em vista a prevenção de reinfecção.

As DST's são agravos que podem ser evitados com ações de prevenção primária, e com exceção das DST's causadas por vírus, existem tratamentos eficazes para todas elas. Logo, o controle das doenças sexualmente transmissíveis é possível, desde que existam programas de prevenção e uma rede de serviços resolutivos (BRASIL, 2002).

Diante do exposto, torna-se evidente a necessidade de incluir o parceiro nas consultas de planejamento familiar a fim de que, junto, o casal possa analisar a possibilidade e o momento de gerar filhos.

O sucesso das consultas depende, portanto, da participação do casal no processo de escolha e adesão ao método de preferência dos dois. Essa participação refere-se não apenas ao comparecimento às consultas, mas também ao interesse em esclarecer dúvidas e utilizar-se da 
liberdade de escolha entre os métodos, mediante apresentação de riscos e benefícios de cada um deles.

Outro fator essencial para a participação efetiva dos parceiros é a educação continuada, incentivando, ao longo das consultas subseqüentes, o esclarecimento de dúvidas sobre temáticas relacionadas à saúde sexual e reprodutiva, de maneira dinâmica que os integre no processo.

Essa temática propõe questionamentos a serem investigados sobre a causa dessa deficiente participação, se devido à falta de interesse dos parceiros ou ao escasso incentivo por parte dos profissionais de saúde.

\section{Referências}

AZEVEDO, R. B.Doenças Sexualmente Transmissíveis. São Paulo: Saúde e Vida, 2002.

BRASIL, Ministério da Saúde. Cadernos da Atenção Básica: HIV/aids, hepatites e outras DST. Brasília-DF, 2006.

BRASIL, Ministério da Saúde. Cadernos da Atenção Básica: Planejamento Famliar. Brasília-DF, 2006.

\section{Sobre as autoras:}

(1) Maria Socorro de Figueiredo Feitosa é Graduada em História pela Faculdade de Formação de Professores de Serra Talhada - FFPST, pós-graduanda em Administração Hospitalar pela Universidade Regional do Cariri - URCA;

(2) Maria Engracia Loiola é Graduada em Pedagogia pela Universidade Regional do Cariri - URCA, professora do Centro Federal de Educação Tecnológica do Ceará - CEFET, doutoranda em Ciências da Educação pela Universidade Nacional de Cuyo - Argentina.

E-mail: engracia.loiola@hotmail.com 